\title{
Baseline Si electrode fabrication and performance for the Battery for Advanced Transportation Technologies Program
}

\author{
Wen Yuan $\dagger$, Mingyan Wu†, Hui Zhao, Xiangyun Song, and Gao Liu* \\ Environmental Energy Technologies Division, \\ Lawrence Berkeley National Laboratory, 1 Cyclotron Rd., Berkeley, CA 94720, \\ U.S.A. \\ Tel.: +1-510-486-7207; fax: +1-510-486-7303; Email:gliu@1bl.gov(G. Liu) \\ $\dagger$ These authors contributed equally to this work
}

\begin{abstract}
Baseline $\mathrm{Si}$ electrodes were developed and characterized based on $\mathrm{Si}$ nanomaterials. Silicon $(\mathrm{Si})$ with a designed nanostructure has attracted much attention as potential anode materials for lithium-ion batteries due to its high gravimetric specific capacity. Because of a resulted poor tap density of Si from the electrode while using nano-sized $\mathrm{Si}$ and also from including other additives like conductive carbon and binder, it is difficult to maintain a high loading of active materials at the anode side in lithium-ion batteries. In this report, we aim to investigate how the thickness of Si-based electrode influences the cycling performance, rate performance and impedance. We also discuss the variation of gravimetric, area and volumetric capacity along with increasing of electrode thickness. It is found that with a thinner electrode of $7 \mu \mathrm{m}$ the volumetric capacity could reach up to $920 \mathrm{mAhcm}^{-3}$ but a poor area capacity of $0.7 \mathrm{mAh} \mathrm{cm} \mathrm{cm}^{-2}$, while a thicker one of $33 \mu \mathrm{m}$ enables to provide a high area capacity up to $1.5 \mathrm{mAh} \mathrm{cm}^{-2}$ and gives a volumetric capacity less than $500 \mathrm{mAhcm}^{-3}$. A cell operated under $0{ }^{\circ} \mathrm{C}$ shows a gravimetric capacity of $2000 \mathrm{mAhg}^{-1}$ after 60 cycles.
\end{abstract}


Keywords: Silicon, lithium-ion batteries, electrode thickness, electrochemical performance, low temperature batteries

\section{Introduction}

Silicon ( $\mathrm{Si}$ ) has been extensively studied as one of the most promising anodes for Li-ion batteries because of its delivering a greater theoretical gravimetric specific capacity (4200 mAh g $\left.\mathrm{m}^{-1}\right)$ over the conventional graphite anode $\left(372 \mathrm{mAh} \mathrm{g}^{-1}\right)$.[1-3]For a volumetric comparison, graphite has a theoretical volumetric capacity about 850 $\mathrm{mAhcm}^{-3}$. For a typical 20 vol \% Si electrodes discussed in Beattie's previous report, it has a volumetric energy density of $1668 \mathrm{mAh} \mathrm{cm}^{-3}$.[4]The gravimetric energy density of Si electrode at the laminate level can easily exceed $3000 \mathrm{mAh} \mathrm{g}^{-1}$ (excluding the current collector), based on classic electrode design, which includes $90 \%$ (by weight) graphite, $10 \%$ of polymer binder and acetylene black (AB) conductive additive, and $30 \%$ porosity. This would be ten times higher than that of the graphite based electrode with the same composition and design. Practical volumetric energy density of graphite electrode is around $400 \mathrm{mAh} \mathrm{cm}^{-3}$ using classic electrode design.[5] Switching from graphite to $\mathrm{Si}$ could potentially improve the volumetric energy density in lithium-ion batteries beyond $1000 \mathrm{mAh} \mathrm{cm}^{-3} \cdot[5-8]$

As forming a $\mathrm{Li}_{4.4} \mathrm{Si}$ alloy from lithium intercalating into $\mathrm{Si}$, a $320 \%$ huge volume expansion occurs when full lithiation on Si.[2, 9, 10]This large volume change leads to a destructive pulverization of $\mathrm{Si}$ as well as electrical contact loss between active materials, which eventually cause a fast capacity fading of battery.[2, 11, 12]Si 
nanostructure designing by taking the advantages of large surface area and porosity, greatly alleviates the mechanical stress during volume changing as well as enhances the electronic connections. The successful examples include Si nano particles,[13-15] Si nanowires,[6, 16] Si/C nanocomposites,[17, 18] and nanoporous $\mathrm{Si}[19-22]$ which effectively addressed the challenge of volume change during lithiation and gave a stable cycling performance of batteries. Unfortunately, such a nano Si structure along with a high porosity packed inefficiently with a low stacking density, which would lower the volumetric energy density, and need to increase the loading of other components including binder and conductive agent leading to more side reactions. High energy density battery with an ordered-structure like Si nanowires has been demonstrated to exhibit a high volumetric energy density in lithium-ion batteries, especially combing with carbon to form $\mathrm{Si} / \mathrm{C}$ composite electrode. Very few examples have been reported on achieving both a high area and volumetric capacity so far. Cui and coworker first developed freestanding nanocomposites made of carbon nanofibers (CNFs) and silicon nanowires (SiNWs) as metal current collector-free anode platforms. This achieved an improved areal capacity up to $5 \mathrm{~mA} \mathrm{~cm}^{-2}$ and a corresponding volumetric capacity of $1429 \mathrm{mAh} \mathrm{cm}^{-3}$.[5]Later on, Cho reported a new architecture consisting of SiNWs internally grown from porous graphite, providing more free spaces to accommodate volume expansion of internally grown $\mathrm{Si}$ during cycling and facilitate electron transport as well. With this strategy, the electrode has a high density of $1.5 \mathrm{gcm}^{-3}$ and the prepared battery exhibits a high volumetric capacity of $1363 \mathrm{mAh}^{-3}$ with high initial coulombic efficiency over 
90\%.[6] Very recently, Cui's group designed a pomegranate-inspired nano structure with void space around single Si nanoparticles in an encapsulated thicker carbon layer, which enable to leave a buffering room for $\mathrm{Si}$ expansion and contraction. After continued lithiation/delithiation, the solid-electrolyte interphase (SEI) layer remained stable with high capacity retention over $97 \%$ after 1000 cycles. And the cycling performance remained stable even when the area capacity increased above $3 \mathrm{mAh}$ $\mathrm{cm}^{-2} \cdot[7]$

Considering complex manufacturing process and high cost of nano-sized $\mathrm{Si}$, and $\mathrm{Si}$ large volume expansion, it is very challenging to develop a Si based material and electrode assembly approach for a practical high capacity $\mathrm{Si}$ electrode. In this study, we selected commercial available pure nano-sized silicon particles, sodium carboxy methyl cellulose (NaCMC) binder and acetylene black to make baseline composite electrodes. Charge/discharge cycling performance, rate performance has been studied while applying different thickness of anodes, especially a full discussion on variation of corresponding gravimetric, area and volumetric specific capacity. This effort is part of the US DOE's Battery for Advance Transportation Technologies program R\&D effort to develop advanced high capacity Si anodes. Baseline Si based electrodes developed at Lawrence Berkeley National Laboratory provide a benchmark for the comparison study of variety of the materials and electrodes developed under the BATT program.

\section{Experimental}


The nano-sized Si particles were experimental sample name Si Nano-Grain from Umicore. Acetylene black as conducting agent was purchased from TIMCAL. To make a baseline electrode, a slurry including $\mathrm{n}$-Si particles (50 wt \%), carboxyl methyl cellulose binder (20 wt \%), poly vinyl alcohol (PVA) (5 wt \%) and acetylene black (25 wt \%) in aqueous solution was homogenized for one hour. The uniform slurry was cast on copper foil. The thickness of electrodes was controlled by doctor blade gap to achieve the desired area capacity loading. Electrolytes were purchased from Novolyte (now part of BASF), including battery-grade lithium hexafluorophosphate (LiPF6) in ethylene carbonate (EC), diethyl carbonate (DEC) and fluoroethylene carbonate (FEC). The composition of electrolyte is $1 \mathrm{M} \mathrm{LiPF}_{6}$ in EC:DEC $=1: 1$ with $10 \%$ FEC by weight. For A Celgard 3501 Separator membrane was purchased from Celgard. Other chemicals were purchased from Sigma Aldrich and used without any further purification. Coin cells were prepared with lithium metal (purchased from FMC Corporation) as counter electrode. The cell fabrication can be found in the literature.[23]The coin cell performance was evaluated with a Maccor Series 4000 Battery Test System in a thermal chamber at $30{ }^{\circ} \mathrm{C}$. For the low temperature study, battery cycling test was performed at $30 \square$ for 10 cycles and switched to $0 \square$ for the rest of 50 cycles at C/10.The C-rate calculation of the Si based electrode is assuming the $\mathrm{Si}$ has the theoretical capacity of 4200 $\mathrm{mAhg}^{-1}$.Electrochemical Impedance Spectroscopy (EIS) were conducted on a VMP galvanostat/potentiostat (Bio-Logic). Si half cells were cycled for 50complete cycles at a C/10 rate, followed by a half lithiation at one extended cycle and rested for 4 
hours before EIS measurement. The sample cells were brought to $10 \mathrm{mV}$ before impedance measurement was taken at $0.01 \mathrm{~Hz}$ to $0.1 \mathrm{MHz}$.

\section{Results and discussions:}

A commercial available $\mathrm{n}$-Si nanoparticle has been selected as an active material. A corresponding laminate (or composite electrode) was made of 50wt $\% \mathrm{Si}, 25 \mathrm{wt} \%$ Acetylene black and $25 \mathrm{wt} \%$ polymer binder (20 wt $\%$ sodium carboxy methyl cellulose (NaCMC) plus 5 wt\% Poly vinyl alcohol (PVA)).The pristine Si particles have sphere structure everywhere with a large size distribution from 50nm to $200 \mathrm{~nm}$. Prepared composite electrode has exhibited large porosity which provides lots of voids for large volume expansion during charge/discharge of Si. The Si particles are glued by a commercial $\mathrm{NaCMC}$ binder and electrical connected by $\mathrm{AB}$ particles.

\section{Table 1. Here}

The electrochemical performance with different thickness of Si electrode was shown in Figure. 1. Three laminates have been prepared with the thickness of $7 \mu \mathrm{m}, 17 \mu \mathrm{m}$, and $33 \mu \mathrm{m}$ respectively. The electrodes were made with doctor blade coating. And the labeled electrode thicknesses in the figures and text are from dry electrode laminates, not the doctor blade gap. Corresponding $\mathrm{Si}$ loading and electrode porosity are calculated and listed in the Table 1 . While increasing the thickness, the packing efficiency of Si particles in the electrode becomes less efficient with a larger porosity. 
Especially an electrode with $33 \mu \mathrm{m}$ thickness holds a porosity of $78 \%$, which would potentially accommodate more $\mathrm{Si}$ volume expansion during lithiation. For a better comparison, all cells under testing were made of cells using Li metal as the counter electrode. As seen in Figure 1a, all three cells showed a very similar capacity fading trend. In the very beginning, a slow lithiation rate of $\mathrm{C} / 25$ is applied at least for three cycles for SEI formation followed by a relatively fast rate of lithiation of $\mathrm{C} / 3$ and delithiation of $\mathrm{C} / 2$ for the rest of the cycling. It is observed that faster fading occur at the first 20 cycles and become more stabilized at extended 30 cycles. It is interesting to see the thinnest electrode of $7 \mu$ malways gives the best performance of gravimetric capacity of $3750 \mathrm{mAh} \mathrm{g}^{-1}$ at a slow rate in initial and then enables to maintain the capacity over $2700 \mathrm{mAh} \mathrm{g}^{-1}$ even after 50 cycles. However as long as we increase the electrode thickness to thicker ones like $17 \mu \mathrm{m}$ and $33 \mu \mathrm{m}$, the gravimetric capacity decreases to $2250 \mathrm{mAh} \mathrm{g}^{-1}$ and $2000 \mathrm{mAh} \mathrm{g}^{-1}$ at the 50th cycle. We attribute this to poor lithium diffusion within a thicker electrode, which results some capacity loss. In the Figure 1b, three thicknesses of electrodes all perform a high first cycle coulombic efficiency of $88 \%$. All cells' columbic efficiency approach $99 \%$ after only 10 cycles.

\section{Figure 1.Here}

Different thickness of electrodes represents different loading of active material. As calculated in Table 1, the $\mathrm{n}$-Si loading of $7 \mu \mathrm{m}, 17 \mu \mathrm{m}$ and $33 \mu \mathrm{m}$ electrode is 0.24 , $0.44,0.74 \mathrm{mg} \mathrm{cm}^{-2}$.As shown in Figure 2 , the area capacity of a thin electrode $(7 \mu \mathrm{m})$ is about $0.7 \mathrm{mAh} \mathrm{cm}$ at a rate of $\mathrm{C} / 10$ after 50 cycles without too much capacity 
fading. Its volumetric capacity is $1280 \mathrm{mAhcm}^{-3}$ at $\mathrm{C} / 25$ and $920 \mathrm{mAh} \mathrm{cm}^{-3}$ after 50 cycles at $\mathrm{C} / 10$. A middle-thick electrode $(17 \mu \mathrm{m})$ gives an area capacity of $1.0 \mathrm{mAh}$ $\mathrm{cm}^{-2}$ and $600 \mathrm{mAh} \mathrm{cm}^{-3}$ at the $50^{\text {th }}$ cycle. With further increase the loading to $0.74 \mathrm{mg}$

$\mathrm{cm}^{-2}(33 \mu \mathrm{m})$, the cell enables to be cycled at a high area capacity over $2.5 \mathrm{mAh} \mathrm{cm}$ and still can maintain a capacity of $1.5 \mathrm{mAh} \mathrm{cm}^{-2}$ after 50 cycles. The corresponding volumetric capacity goes down to only $420 \mathrm{mAh} \mathrm{cm}^{-3}$.

\section{Figure 2.Here}

Further, we investigated the symmetric rate capability with the various rates stepwise increased from $\mathrm{C} / 25$ to $20 \mathrm{C}$, as shown in Figure 3.For the thin electrode, it can achieve capacities of 4090, 3990, 3740, 3060, 2500, 2080, 1340, 640, $115 \mathrm{mAhg}^{-1}$ at current rates of $\mathrm{C} / 25, \mathrm{C} / 10, \mathrm{C} / 5, \mathrm{C} / 2,1 \mathrm{C}, 2 \mathrm{C}, 5 \mathrm{C}, 10 \mathrm{C}$ and $20 \mathrm{C}$ respectively. The capacity of a thicker electrode varies from $3200 \mathrm{mAh} \mathrm{g}^{-1}$ to zero at different charge/discharge rates with a dramatic reduce starting from $\mathrm{C} / 2$. It is shown in the Figure 3 that the thinner electrode demonstrated a better rate performance than the thick electrode, which is also consistent with our cycling performance results previously. In a non-symmetric rate performance test, we fixed all the lithiation rate at $\mathrm{C} / 25$ with delithiation varied from $\mathrm{C} / 25$ to $20 \mathrm{C}$. It is shown that both the thin electrode and thick electrode exhibit good performance with a capacity over 2000 $\mathrm{mAhg}^{-1}$ at 10C. However at 20C, thin electrode gives a capacity above 1000 $\mathrm{mAhg}^{-1}$ while thick electrode falls down to only $200 \mathrm{mAh} \mathrm{g}^{-1}$. With the comparison to the symmetric rate performance previously, it is concluded that lithiation step is 
perhaps the performance elimited step in our system and thin electrodes always perform better at various $\mathrm{C}$ rate.

\section{Figure 3.Here}

The cell impedance with different electrode thickness has been taken as shown in Figure 4. Our initial hypothesis was thicker electrode would give a high resistance after long time cycling. However while using a thicker electrode, it turned out to have smaller impedance rather than a thinner one. As we considered active area for impedance is not just simply an area of electrode, it should also consider a larger electrode porosity meaning a higher active area. Thus for a thicker electrode, it gave a larger active area than a thinner one, which showed smaller impedance.

\section{Figure 4.Here}

For a potential application for electric vehicle, the battery will experience at low temperature, depending on the location and seasons of the vehicle being used. Here we study the low temperature cycling performance based on using the $\mathrm{n}-\mathrm{Si} / \mathrm{NaCMC} / \mathrm{PVA} / \mathrm{AB}$ thin electrode. The electrolyte used in this study is a $1 \mathrm{M} \mathrm{LiPF}_{6}$ in an EC/DEC mixture with an FEC as additive, which is the same as the electrolyte used at $30 \square$. It is apparently the cell with a thin electrode can suffer from a low

temperature of $0 \square$ and maintain over $62 \%$ capacity about $2000 \mathrm{mAh} \mathrm{g}^{-1}$ after sixty cycles in the Figure 5. However, a high loading cell with double thicker electrode operating cannot work very well at low temperature and fade very quickly after the 
cell switching from the condition of $30 \square$ to $0 \square$, which is consistent with the trend at the room temperature comparing between thin and thicker electrode. Ongoing research will focus on finding an optimal electrolyte which enables the high loading Si-based lithium battery suffered at the low temperature.

\section{Figure 5.Here}

\section{Conclusion:}

A composite electrode containing nano-sized $\mathrm{Si}, \mathrm{NaCMC}$ and $\mathrm{AB}$ was made with different thickness $(7 \mu \mathrm{m}, 17 \mu \mathrm{m}$ and $33 \mu \mathrm{m})$. The fabricated cells all showed a high gravimetric capacity over $2000 \mathrm{mAhg}^{-1}$ after 50 cycles as well as a coulombic efficiency of $99 \%$, which demonstrated that the idea of introducing large surface area nano $\mathrm{Si}$ could greatly improve the electrochemical performance of Si-based lithium-ion batteries. Through the study of symmetric and non-symmetric rate test, Si-based lithium ion battery enable to perform a high specific capacity over 1000 $\mathrm{mAhg}^{-1}$ at $1 \mathrm{C}$ charge/discharge either using thin or thick electrode. Considering various thickness of electrodes having different loadings of silicon, the cells performed different level of area capacity and volumetric capacity of $\mathrm{Si}$. It is found that the battery using Si nanoparticles without any structure designing is difficult to reach a high area capacity, which cannot compete with a conventional battery using graphite. In this report, an area capacity up to $2.5 \mathrm{mAh} \mathrm{cm}^{-2}$ is achieved at slow charge/discharge rate using a thicker electrode but fade to $1.5 \mathrm{~mA} \mathrm{~cm}^{-2}$ after 50 cycles at a fast rate. However, volumetric capacity obtained from the same electrode only 
gave a low value of $420 \mathrm{mAh} \mathrm{cm}^{-3}$ when we tried to push the Si loading up, which didn't improve much compared to a graphite cell. Through this thickness study, we aim to test the applicability of $\mathrm{Si}$ as electrodes in lithium-ion batteries and deliver the information to people who also feel interests on his field that 1) making a stabilized and high gravimetric capacity is not a secret and easy to achieve, but 2) making an applicable battery with both a high area capacity and volumetric capacity needs to be explored. Ongoing research will focus on finding a scalable and cheap nano or micro-sized Si materials[14] as anodes and making an applicable battery with both high area capacity and volumetric capacity not limited at room temperature but also aimed to low temperature application.

\section{Acknowledgement:}

This work was funded by the Assistant Secretary for Energy Efficiency, Office of Vehicle Technologies of the U.S. Department of Energy (U.S. DOE) under contract no. DE-AC02-05CH 11231 under the Batteries for Advanced Transportation Technologies (BATT)Program.

\section{References:}

[1] B.A. Boukamp, G.C. Lesh, R.A. Huggins, All-Solid Lithium Electrodes with Mixed-Conductor Matrix, J Electrochem Soc, 128 (1981) 725-729.

[2] J. Li, J.R. Dahn, An in situ X-ray diffraction study of the reaction of Li with crystalline Si, J Electrochem Soc, 154 (2007) A156-A161.

[3] N. Yuca, H. Zhao, X.Y. Song, M.F. Dogdu, W. Yuan, Y.B. Fu, V.S. Battaglia, X.C. Xiao, G. Liu, A Systematic Investigation of Polymer Binder Flexibility on the Electrode Performance of Lithium-Ion Batteries, Acs Appl Mater Inter, 6 (2014) 17111-17118.

[4] S.D. Beattie, D. Larcher, M. Morcrette, B. Simon, J.M. Tarascon, Si electrodes for 
li-ion batteries - A new way to look at an old problem, J Electrochem Soc, 155 (2008) A158-A163.

[5] J.W. Choi, L.B. Hu, L.F. Cui, J.R. McDonough, Y. Cui, Metal current collector-free freestanding silicon-carbon 1D nanocomposites for ultralight anodes in lithium ion batteries, J Power Sources, 195 (2010) 8311-8316.

[6] S. Jeong, J.P. Lee, M. Ko, G. Kim, S. Park, J. Cho, Etched Graphite with Internally Grown Si Nanowires from Pores as an Anode for High Density Li-Ion Batteries, Nano Lett, 13 (2013) 3403-3407.

[7] N. Liu, Z.D. Lu, J. Zhao, M.T. McDowell, H.W. Lee, W.T. Zhao, Y. Cui, A pomegranate-inspired nanoscale design for large-volume-change lithium battery anodes, Nat. Nanotechnol., 9 (2014) 187-192.

[8] W. Yuan, H. Zhao, H.Y. Hu, S. Wang, G.L. Baker, Synthesis and Characterization of the Hole-Conducting Silica/Polymer Nanocomposites and Application in Solid-State Dye-Sensitized Solar Cell, Acs Appl Mater Inter, 5 (2013) 4155-4161.

[9] M.N. Obrovac, L.J. Krause, Reversible cycling of crystalline silicon powder, J Electrochem Soc, 154 (2007) A103-A108.

[10] J.H. Ryu, J.W. Kim, Y.E. Sung, S.M. Oh, Failure modes of silicon powder negative electrode in lithium secondary batteries, Electrochem Solid State Lett Electrochem. Solid State Lett., 7 (2004) A306-A309.

[11] J. Christensen, J. Newman, Stress generation and fracture in lithium insertion materials, J Solid State Electrochem, 10 (2006) 293-319.

[12] S. Renganathan, G. Sikha, S. Santhanagopalan, R.E. White, Theoretical Analysis of Stresses in a Lithium Ion Cell, J Electrochem Soc, 157 (2010) A155-A163.

[13] M.Y. Wu, X.C. Xiao, N. Vukmirovic, S.D. Xun, P.K. Das, X.Y. Song, P. Olalde-Velasco, D.D. Wang, A.Z. Weber, L.W. Wang, V.S. Battaglia, W.L. Yang, G. Liu, Toward an Ideal Polymer Binder Design for High-Capacity Battery Anodes, J Am Chem Soc, 135 (2013) 12048-12056.

[14] M.Y. Wu, J.E.C. Sabisch, X.Y. Song, A.M. Minor, V.S. Battaglia, G. Liu, In Situ Formed Si Nanoparticle Network with Micron-Sized Si Particles for Lithium-Ion Battery Anodes, Nano Lett, 13 (2013) 5397-5402.

[15] H.Y. Hu, W. Yuan, H. Zhao, G.L. Baker, A Novel Polymer Gel Electrolyte: Direct Polymerization of Ionic Liquid from Surface of Silica Nanoparticles, J Polym Sci Pol Chem, 52 (2014) 121-127.

[16] C.K. Chan, H.L. Peng, G. Liu, K. McIlwrath, X.F. Zhang, R.A. Huggins, Y. Cui, High-performance lithium battery anodes using silicon nanowires, Nat. Nanotechnol., 3 (2008) 31-35.

[17] A. Magasinski, P. Dixon, B. Hertzberg, A. Kvit, J. Ayala, G. Yushin, High-performance lithium-ion anodes using a hierarchical bottom-up approach, Nature Mater, 9 (2010) 353-358.

[18] Z. Jia, W. Yuan, H. Zhao, H.Y. Hu, G.L. Baker, Composite electrolytes comprised of poly(ethylene oxide) and silica nanoparticles with grafted poly(ethylene oxide)-containing polymers, Rsc Adv, 4 (2014) 41087-41098.

[19] M.Y. Ge, J.P. Rong, X. Fang, C.W. Zhou, Porous Doped Silicon Nanowires for Lithium Ion Battery Anode with Long Cycle Life, Nano Lett, 12 (2012) 2318-2323. 
[20] Y. Zhao, X.Z. Liu, H.Q. Li, T.Y. Zhai, H.S. Zhou, Hierarchical micro/nano porous silicon Li-ion battery anodes, Chem Commun, 48 (2012) 5079-5081.

[21] B.M. Bang, J.I. Lee, H. Kim, J. Cho, S. Park, High-Performance Macroporous Bulk Silicon Anodes Synthesized by Template-Free Chemical Etching, Adv Energy Mater, 2 (2012) 878-883.

[22] H. Kim, B. Han, J. Choo, J. Cho, Three-Dimensional Porous Silicon Particles for Use in High-Performance Lithium Secondary Batteries, Angew Chem Int Edit, 47 (2008) 10151-10154.

[23] G. Liu, H. Zheng, A.S. Simens, A.M. Minor, X. Song, V.S. Battaglia, Optimization of acetylene black conductive additive and PVDF composition for high-power rechargeable lithium-ion cells, J Electrochem Soc, 154 (2007) A1129-A1134.

\section{Table and Figures captions:}

Table 1. Thickness, Si loading and porosity of Si electrodes

Figure 1. a) Cycling performance (Gravimetric Specific Capacity vs. Cycle No.) of $\mathrm{n}$-Si/NaCMC/PVA/AB electrodes with different thickness (7 $\mu \mathrm{m}, 17 \mu \mathrm{mand} 33 \mu \mathrm{m})$ and their b) corresponding coulombic efficiency.

Figure 2.Cycling performance of $\mathrm{n}-\mathrm{Si} / \mathrm{NaCMC} / \mathrm{PVA} / \mathrm{AB}$ electrodes with different thickness $(7 \mu \mathrm{m}, 17 \mu \mathrm{mand} 33 \mu \mathrm{m})$ : a) Area Specific Capacity vs. Cycle No.and b) Volumetric Specific Capacity vs. Cycle No.

Figure 3.Symmetric and non-symmetric rate performance of thin and thick electrode at different charge/discharge rates from $\mathrm{C} / 25$ to $20 \mathrm{C}$. $\left(1 \mathrm{C}=4.2 \mathrm{Ag}^{-1}\right)$

Figure 4.Cell impedance based on two different thickness electrodes. Impedance was recorded after fifty cycles at $\mathrm{C} / 10$, and the rest were recorded $4 \mathrm{~h}$ after half-lithiation in the next cycle.

Figure 5. Cycling performance of $n-\mathrm{Si} / \mathrm{NaCMC} / \mathrm{PVA} / \mathrm{AB}$ thin electrode at $30 \square$ (ten cycles) and $0 \square$ (fifty cycles) at C/10 on two different thickness electrodes.

Table 1. Thickness, Si loading and porosity of Si electrodes

\begin{tabular}{cccc}
\hline Entry & Thickness & Si loading & Porosity \\
\hline 1 & $7 \mu \mathrm{m}$ & $0.24 \mathrm{mg} \mathrm{cm}^{-2}$ & $65 \%$ \\
2 & $17 \mu \mathrm{m}$ & $0.44 \mathrm{mg} \mathrm{cm}^{-2}$ & $72 \%$ \\
3 & $33 \mu \mathrm{m}$ & $0.74 \mathrm{mg} \mathrm{cm}^{-2}$ & $78 \%$ \\
\hline
\end{tabular}

Density of $\mathrm{Si}, \mathrm{NaCMC}$ and $\mathrm{AB}$ is $2.33 \mathrm{gcm}^{-3}, 1.59 \mathrm{gcm}^{-3}$ and $1.95 \mathrm{gcm}^{-3}$, respectively. 
Click here to download high resolution image

a)

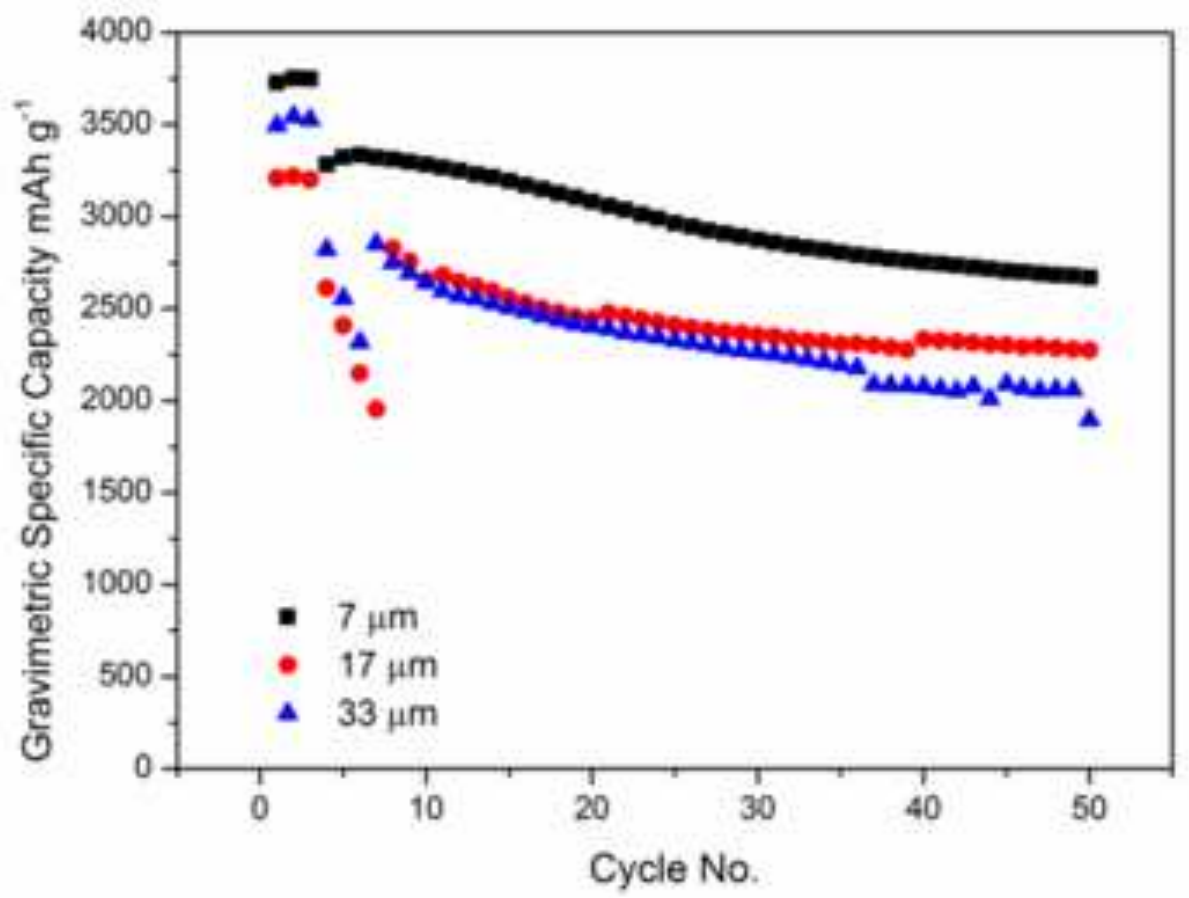

b)

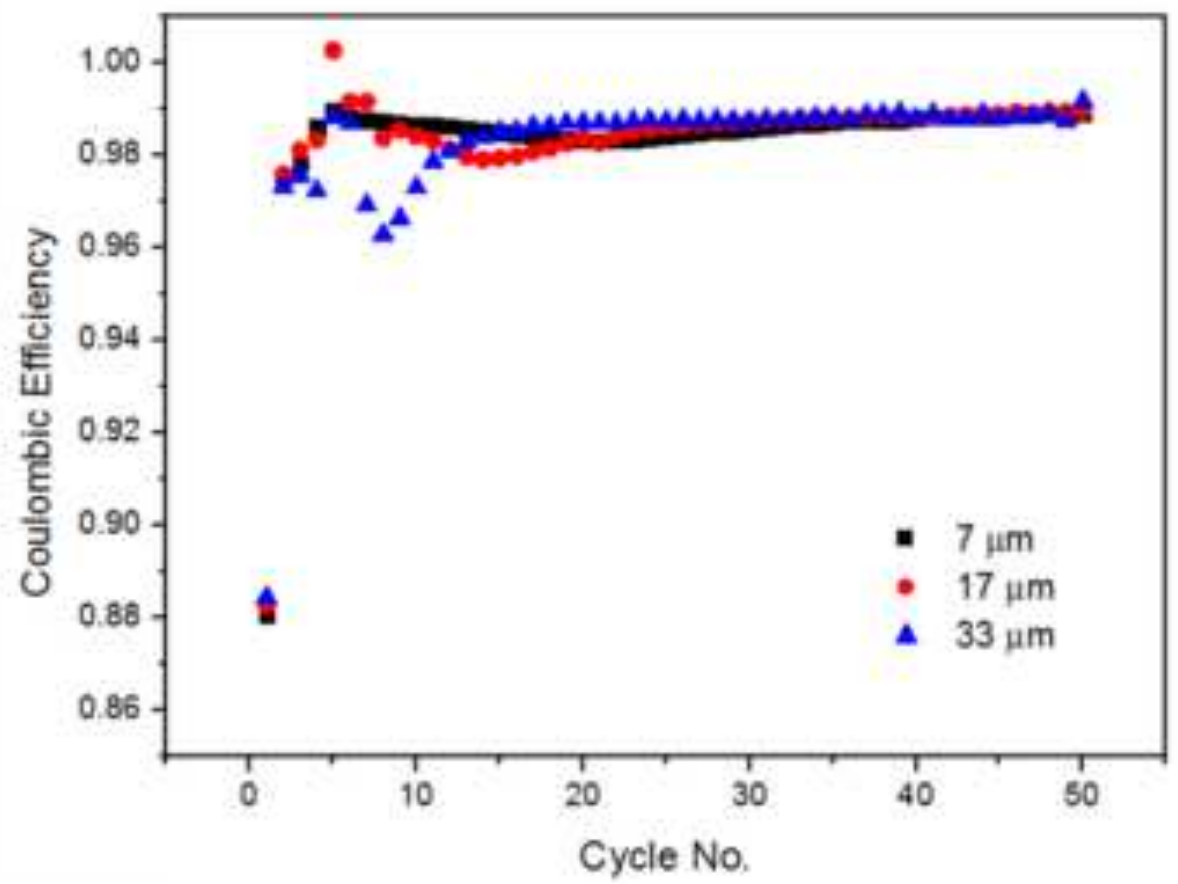


a)

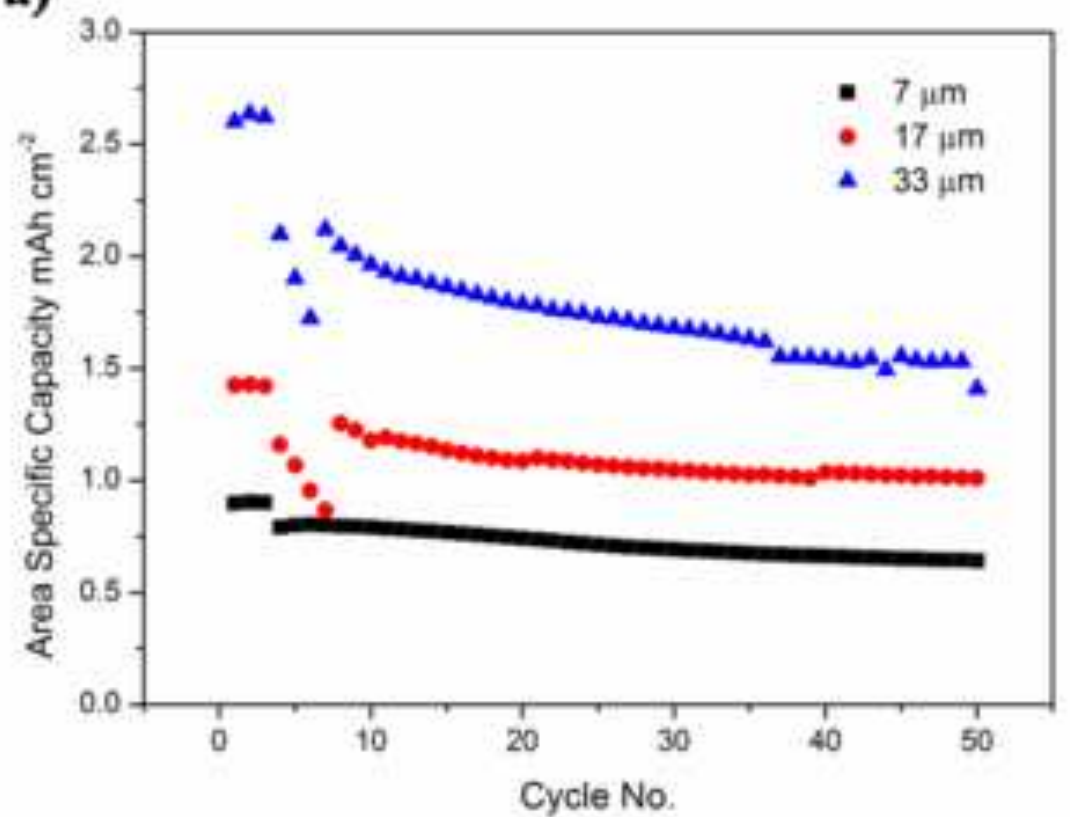

b)

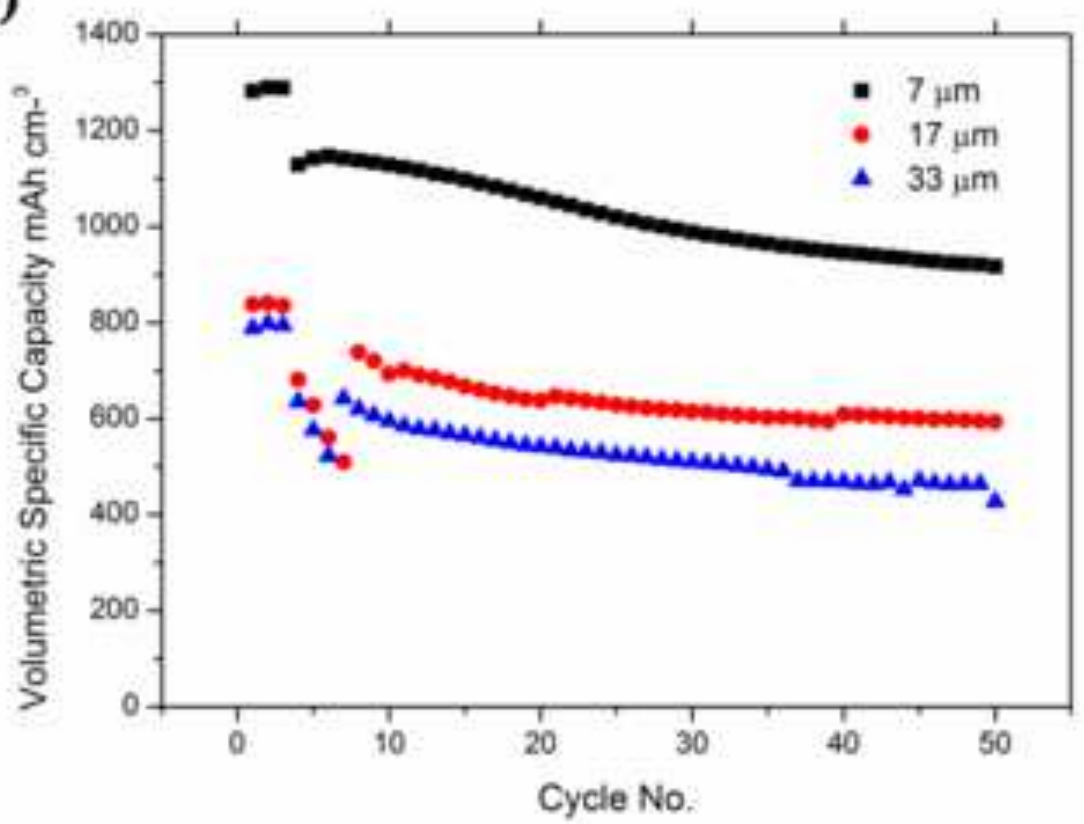




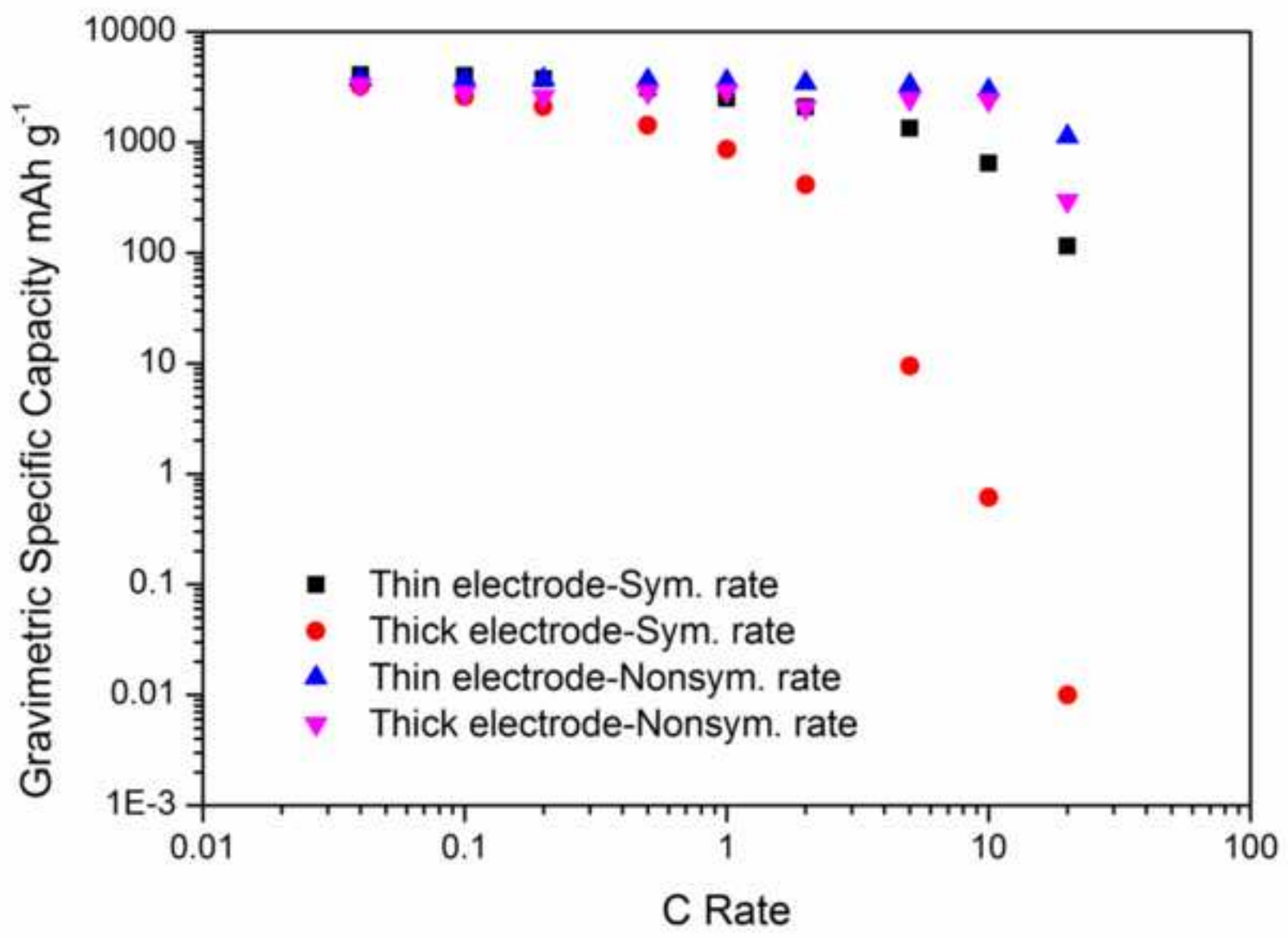




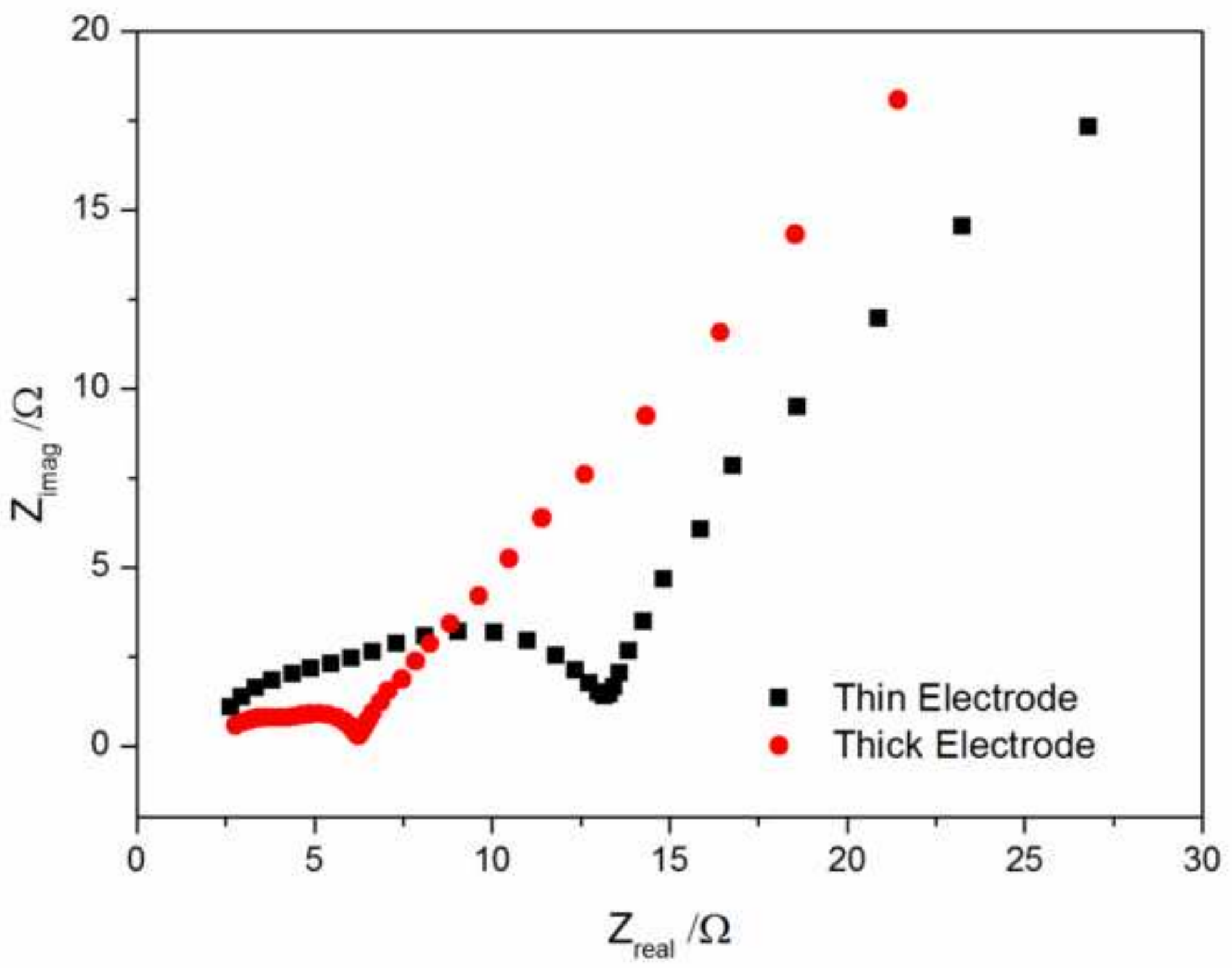


